\title{
LAS LEYENDAS DE LAS MINAS DEL TISINGAL Y LA ESTRELLA EN COSTA RICA
}

\author{
Percy Denyer
Escuela Centroamericana de Geología, Apdo. 214-2060 Universidad de Costa Rica Correo electrónico:pdenyer@geologia.ucr.ac.cr

(Recibido 18/6/2001; Aceptado 12/7/2001)

\begin{abstract}
Since the Spaniard conquering, there are legends about the existence of some very rich mines near Tisingal and La Estrella located in Costa Rica, first reported by Juan Vázquez de Coronado. During the XIX century, there were at least ten expeditions looking for the famous mines. At the end of the XIX century, occurred an intention of colonization and exploitation of Talamanca. The geologist William M. Gabb denied the existence of big mines and von Frantzius considered that they may be located in Honduras.
\end{abstract}

RESUMEN: Las leyendas sobre la existencia de las ricas minas del Tisingal y La Estrella en Costa Rica, provienen directamente de los primeros conquistadores españoles, especialmente Juan Vázquez de Coronado y, perduran hasta el siglo XIX, cuando se hacen, por lo menos una decena de expediciones en busca de las minas de oro, culminando con un serio intento de colonización y explotación de Talamanca. Las investigaciones del geólogo William M. Gabb rechazan la idea de la existencia de grandes minas en Talamanca y von Frantzius considera que el Tisingal se encontraba en Honduras.

\section{INTRODUCCIÓN}

Después de la llegada de los españoles, se da una evolución divergente de las diferentes regiones de América. Dentro de este contexto, Costa Rica parece ser una de las regiones más pobres, cuyo nombre se debe más a lo que se esperaba encontrar, basada en la joyería aborigen observada por los españoles, que propiamente en las riquezas halladas por los conquistadores. Sin embargo, desde el período de la conquista han perdurado leyendas sobre la existencia de grandes minas en nuestro territorio, lo que ha tenido repercusiones importantes en la historia de Costa Rica. Se habla de Nuevo Cartago o Costa Rica desde 1541, por Diego Gutiérrez y es usado por Juan de Estrada Rávago y Artieda Cherinos, en 1561 y 1574 respectivamente. Von Frantzius (1882), sintetiza la razón para nombrar a Costa Rica de la siguiente manera: "El nombre de Costa Rica fué dado al país, no por las riquezas que en él se enontraron precisamente, sino por las que se esperaban". Desde que Cristóbal Colón estuvo en Cariari (puerto Limón) en setiembre de 1502, había quedado impresionado con el oro que portaban los aborígenes (Ferrero, 2000), dando origen que a nuestro territorio se lo 
mencionara como Costa Rica en 1539 (Alvarado et al., 1991). Sin embargo, Jorge Enrique Güier, en el prólogo del libro Historia General de Costa Rica (Rivas et al., 1989), señala que el responsable del nombre de Costa Rica fue el gobernador de Nicaragua, Don Rodrigo Contreras en el año 1541 o 1542 . Con respecto al nombre de Tisingal, von Frantzius (1882) indica que este vocablo se ha escrito también como Tinsingal, Tiusigal, Tissingal, lo que puede estar haciendo referencia a Tegucigalpa, conocida en la época como Tafuzgalpa o tierra de oro.

En este trabajo se tratarán dos temas, que los relaciona el deseo del ser humano por la explotación de los recursos naturales, teniendo como fin el enriquecimiento material. No se pretende hacer un estudio muy novedoso, sino solo desempolvar y entresacar algunas ideas e interpretaciones de investigadores de finales de siglo XIX, como las de Alejandro von Frantzius (1882) y Ernesto Melliss (1891), que incorporan las anotaciones de León Fernández el primero y de Francisco María Iglesias el segundo, el libro sobre el oro en Costa Rica, de Ricardo Jinesta (1938), así como otros investigadores más recientes, que han dado aportes sobre la historia de la minería, con el objeto de comparar los diferentes puntos de vista, a la luz de las historias que se han tejido sobre las fabulosas minas de Costa Rica (Araya Pochet, 1976; Fuentealba, 1977; Ulloa, 1979; Castillo, 1983; Villalta, 1986).

La mayoría de las transcripciones contienen numerosos errores ortográficos, que se han respetado con miras en darle una mejor perspectiva histórica, se ha evitado el uso de sic., para darle más fluidez a la lectura.

\section{EL TISINGAL Y LA ESTRELLA DURANTE LA CONQUISTA ESPAÑOLA}

Las leyendas sobre minas de oro difundidas durante la Colonia provienen directamente de los primeros conquistadores españoles e involucran la zona conocida como Talamanca, que correspondía con un área de unos 4000 $\mathrm{km}^{2}$, que incluía el valle del río Sixaola (Tarire o Sicsaola), el este del actual río La Estrella (Tain-hi), y Bocas del Toro (Escudo de Veraguas) y partes de la actual cordillera de Talamanca (Pittier, 1983) (ver Fig. 1).

La referencia más antigua del nombre de Tisingal parece ser de 1786, del Diccionario Geográfico-Histórico de las Indias Occidentales o América, de Alcedo (von Frantzius, 1882), textualmente dice: "Diéronle el nombre de CostaRica los Españoles por el mucho oro y plata que encierra en sus minas; y de la que llaman Tisingal se ha sacado poco ménos riqueza que del cerro de Potosí en el Perú, \&."

Al español Gil González, los indígenas le dieron mucho oro en 1522; en 1528 ya Pedrarias Dávila habla del mucho oro que había en Nicaragua y Costa Rica. Herrera, habla de tesoros mineros en Costa Rica, con respecto a la fundación de la villa de Bruselas en las cercanías del Golfo de Nicoya dice: “...por una parte tenía el mar, por otras los llanos, y por la tercera, la sierra de las minas." (Jinesta, 1938).

El principal conquistador que deja constancia de la aparente riqueza de las minas de Costa Rica es Juan Vázquez de Coronado, quien en carta al Rey D. Felipe II escribió desde Nueva Cartago el 11 de diciembre de 1562, refiriéndose a Costa Rica:

"La tierra es de las buenas que yo he visto en Indias y a mi ver no le haze ventaja ninguna de la Nueva España ni del distrito, porque he visto todas las mas y governado en nombre de vuestra Majestad algunas.

Danse muy bien ganados de todas maneras. Los naturales della son vivos de ingenio, belicosos, mayores de cuerpo que otros, bien hechos; imitan en la sotileza de las contrataciones a los mexicanos [de Talamanca]; tienen ropa de algodon por extremo buena, gran cantidad de oro de todos quilates. Mostroseles codicia dello en los principios y hanlo escondido. Es forçoso que aya minas en una gran cantidad, y no se aver descubierto ha causado la poca gente que tubo el licenciado Juan de Cavallon que nunca 

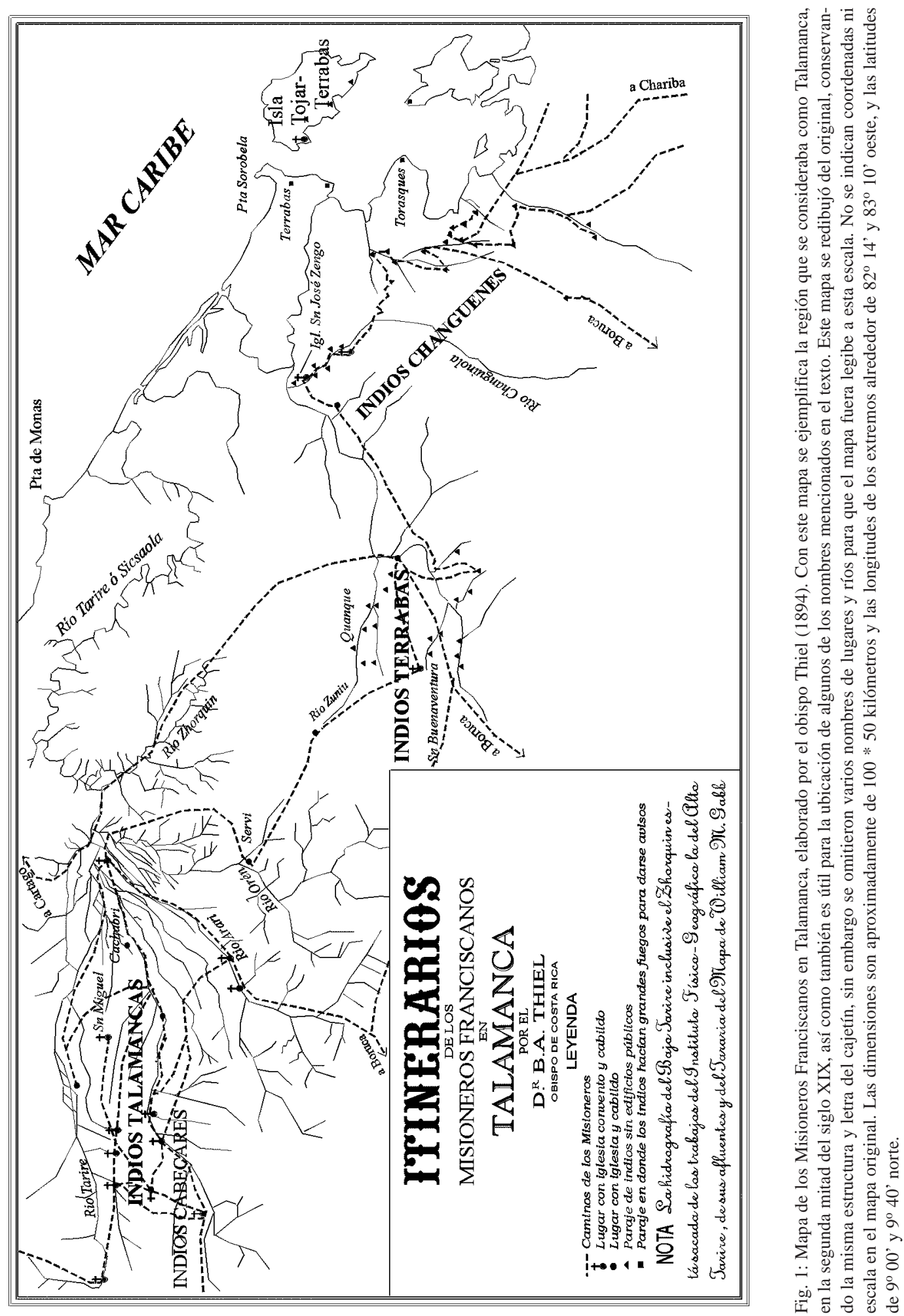
oso enviar a parte ninguna de asiento sino paso a descubrir la tierra." (Fernández Guardia, 1908, p. 13).

El deseo de Coronado de encontrar la fuente del oro de los indígenas se hace evidente en la siguiente frase, escrita en 1563: "Inquiri donde sacaban el oro y dixeron que cada uno destos pueblos tenia un rio donde los sacaba, dieron noticia de como se sacava. No pude acabar con ellos que por bien me lo fuesen a mostrar; dixeron qu darian un rio quatro jornadas de alli, de un pueblos quellos despoblaron con guerra, que se llama Ucacara." (Fernández Guardia, 1908, p. 36).

Coronado deja constancia en los archivos de Sevilla, sobre la situación del río de La Estrella, tomada de registros de minas del año de 1564, textualmente se lee lo siguiente:

"En el palenque, y pueblo de Quequexque, que es la cordillera de la mar del Norte, provincia de Cartago y Costa Rica, en cinco dias del mes de marzo de 1,564 años, el muy magnifico Señor Juan Vásquez de Coronado, justicia mayor y Capitán general de estas dichas provincias por S.M., Su Justicia Mayor, juez de la recidencia vicitador general de la de Nicaragua, por ante mí Cristobal de Madrigal, escribano de gobernación y de su Juzgado y Campo, dijo que, por cuanto su merced ha descubierto oro en el rio Estrella con sus negros, que es en frente del camino de Guteurú; el cual dicho río de la Estrella pasa por pueblos de estas provincias y vá a salir case las islas de Iovobaro y bahia Almirante; y el dicho oro es gran cantidad, y se haya y toma lo que del dicho rio se ha cateado; por cuanto que su merced se estacaba por descubridor donde un árbol, cuyas raices cortaron los negros para catear, que queda en pié, hasta una ceiba que está río arriba ..., y el dicho rio de la Estrella dista a lo que va de la ciudad de Cartago cincuenta leguas poco mas o menos, de tierra de guerra..." (Arch. Nac. C.R., Albúm de Figueroa, p. 140 y 142).
No deben haber sido tan ricos los yacimientos, puesto que Vázquez de Coronado gasta más de veinte mil pesos en la conquista de Costa Rica, con la esperanza de pagarlos con los ricos lavaderos de La Estrella, pero no pudo recuperar tal cantidad. Otro conquistador, Juan Dávila, en carta al rey Felipe II en 1566, opina que Vázquez de Coronado exageraba estas riquezas (Fernández Guardia, 1913, p. 250-265). Así pues, las maravillas auríferas de Talamanca nacieron de una exageración, hasta convertirse en casi en un mito.

Estrada Rávago dice en 1572 que las cordilleras que corren hacia el norte son ricas en oro y plata. En 1573 el rey pide el diezmo sobre el oro, la plata, perlas y piedras preciosas, se habla entonces de hacer unas Ordenanzas para la minería, pues había mucho oro en Pocosol, río San Juan, Quepo, Coctu y Turucaca. En el valle de Landecho, que se extendía entre Río Grande y La Barranca descubren una mina de cobre, en 1587 (Jinesta, 1938).

En el siglo XVII persistían las creencias de los yacimientos de oro, pues Andrés Arias Maldonado y Velazco escribe en 1659: "Por esta parte [refiriéndose al río Coén] he reconocido y he visto el perderse hacer la conquista de Talamanca y valle del Duy, tan celebrado en Indias por su mucha abundancia de oro..." (Fernández, 1889, p. 214). En 1674 en un informe al Presidente de la Audiencia de Guatemala se dice: "Los Talamancas son indios levantados más há de 60 años que quemaron la ciudad de la Talamanca y degollaron los españoles; son dueños del río de la Estrella tan conocido por el mucho oro que cría" (Fernández, 1889, p. 251.

En el siglo XVIII prácticamente no existen mayores referencias sobre hallazgos, denuncios, etc. En 1783 se dictan las Ordenanzas de Minería para la Nueva España, que constaban de 314 artículos, para la regulación de la minería en las nuevas colonias españolas (Ulloa, 1979).

Es difícil discernir sobre la veracidad de los relatos de los conquistadores españoles, pues de hecho los indígenas andaban con hermosos adornos de oro y piedras preciosas. Pero distinguir las localidades mineras con base en los ornamentos que se usaban resulta muy peligroso, pues existía un comercio muy diversificado, previo al 
período colonial. Por otro lado, la única minería de que se habla parece ser de yacimientos de placer, por ejemplo cuando se explican los laboreos mineros se describe lo siguiente: "Los indios recogían los granitos de oro en los ríos y quebradas, lavando las arenas; y con las pepitas de mayor tamaño hacían la patenas o también, con los residuos de la fundición, valiéndose de mazas de piedra para extender y laminar el metal." (Jinesta, 1938, p. 6).

Haciendo una analogía entre los relatos y los conocimientos actuales, parece muy lógico pensar que gran parte del oro provenía del Pacífico Sur del país, de los ricos yacimientos auríferos de Osa, Burica y alrededores (Alvarado et al., 1991). Por ejemplo Juan Vázquez de Coronado se refiere a la zona de Coctu y Quepos de la siguiente manera, en 1563: "Estos naturales son riquísimos. Tienen continua guerra con sus comarcanos por robarse el oro que sacan de las minas... La noticia desta tierra en lo que toca al oro es que cada pueblo tiene por heredad un rio donde saca oro, y a mi solamente me declararon uno, quatro jornadas de Coctu, que era de un pueblo despoblado, que los comarcanos con guerra abian acabado los vezinos del por tomarles el oro... Están estas provincias de Turucaca y Coctu principio del valle de Gueymi, frontero del golfo Dosa, entre las dos cordilleras del Sur y del Norte, diez y ocho leguas, a lo que se cree, de la mar del Norte y doze que yo andube de la del Sur, en las faldas de la cordillera de la mar del Norte, hacia la banda Sur" (Fernández Guardia, 1908, p. 51-52.

Vázquez de Coronado, parece que exageró el tipo y tamaño de las minas de Costa Rica, pues incluso en algunos escritos las compara con distritos mineros como los de Potosí, en Bolivia, cosa que a toda vista no tiene comparación. Se dice que después de la sublevación de los indios de Talamanca del 29 de julio de 1610, que produjo el incendio y abandono de la ciudad de Santiago de Talamanca, fundada a orillas del río Tarire (Sixaola), se perdieron las vetas. Sin embargo, cabe notar que el gobernador del valle del Duy y de los Mexicanos, tenía jurisdicción privativa en la ciudad de Santiago y, en el momento de la sublevación se encontraba en la ciudad de Cartago, por lo que hay seguridad de que no todos los conocedores de las riquezas de Talamanca murieron. En los documentos sobre la sublevación de 1610 , no existe ninguna referencia sobre las minas en explotación, aunque se conoce una protesta del gobernador de Costa Rica, Juan Ocon y Trillo, donde se refiere que es una región donde se "tenía noticia de minas de oro" (Fernández, 1882 , p. 24-27). Por otro lado en las colonias españolas se pagaba a la corona un derecho por el oro que se extraía, que se denominaba quinto; y debería existir un estado financiero en Guatemala o en España, de lo cual no se ha encontrado ninguna constancia (Fernández, 1882, p. 24).

\section{LA FIEBRE DEL ORO DURANTE EL SIGLO XIX}

Para entender mejor la situación general del país, dentro del contexto histórico y la posible reacción ante el enriquecimiento por la búsqueda y explotación de metales, haremos un resumen de las bonanzas de oro del siglo XIX, que primeramente abarcan de 1821 a 1843 , y posteriormente se inicia un nuevo período a partir de 1890, hasta 1930 (Araya Pochet, 1976).

El auge de la minería en el país, durante esta época, hizo factible la idea de que que las famosas minas del Tisingal estuvieran en Costa Rica. Esta bonanza económica a partir de la explotación de metales acrecenta la codicia y hace que no sea tan descabellada la idea de que 200 años atrás los españoles sacaban enormes cantidades de oro del país.

Durante la primera mitad del siglo XIX, el oro y la plata se convierten en el principal recurso de explotación nacional. Costa Rica despega económicamente gracias a la exportación de los metales, la riqueza obtenida es utilizada por los empresarios para la compra de implementos para fomentar la agricultura y, de ahí el desarrollo agrícola que caracteriza a la Costa Rica del siglo XX.

A partir del año 1815, empieza a generarse la fiebre del oro en Costa Rica, después del descubrimiento de yacimientos auríferos en los montes del Aguacate. Este hallazgo lo hizo el 
Obispo García Jeréz, quien describe "que los guijos de la superficie del terreno parecían contener oro ó plata, y dijo á sus compañeros que había toda posibilidad que en ese lugar se encontraban minas de estos metales. Un vecino de Cartago, don Santos Lombardo, que venía entre los delegados, llevó consigo varias muestras de los minerales y pronto después averiguó que contenían mucho oro." (Mellis, 1891).

Posteriormente, el 15 de mayo de 1820 , Santos Lombardo hizo el primer denuncio de la mina conocida después como "Sacra Familia". El contrato de ese denuncio, incluido en el Primer Libro de Asiento y Denuncias de Vetas de Minas de Oro y de Plata de la Provincia de Costa Rica, dice lo siguiente:

\section{"1. En la ciudad de Cartago, Provincia de Costa Rica en el Reyno de Guatemala, á lo quince dias del mes de Mayo, lunes a las quatro horas de la tarde, se presentó en este Gobierno por el Capitan del Es- quadron urbano de Fernando 7E. Dn. Jo- sé Santos Lombardo, en compañía de su hermano el Ayudante mayor del mismo Esquadron Dn. Rafael Gallegos, denun- ciando una Veta de Mina de Oro y Plata sita en el paraxe nombrado la Montaña del Aguacate, en el sitio conocido por el nombre de Sacra Familia; y en conformi- dad de lo mandado en la Real Ordenanza de Mineria al Art. 4 tit. 6, se decretó con- cediendo licencia a los denunciantes para que la trabaxea. Fha ut supra." [Firmado por Juan Manuel Cañas, último goberna- dor de la provincia de San José. Revista de Archivos Nacionales 1938(3): p. 170].}

Entre este primer denuncio y el segundo pasaron 18 meses, cuando el 3 de diciembre de 1821 Don Nicolás y Don Pio Castro y los Presbiteros Don José Antonio y Don Vicente Castro denuncian una veta de oro en Vista del Mar (Montes del Aguacate) [ídem, p.171]. Entre 1822 y 1823 crecen considerablemente los denucios de vetas de oro en el Aguacate y, a partir de 1824 se crea la Diputación de Minería, que se encarga de conocer los denuncios mineros. Para 1840 habían alrededor de 200 denuncios mineros, en 5 libros de registros [ídem, p. 169-539].

El 26 de junio de 1830, Juan Mora Fernández dictó, en el decreto 216, las Ordenanzas de Minería, donde se estableció el Juzgado de Minas. En estas Ordenanzas se fijaban restricciones y se perdía el derecho de explotación si se pasaba un tiempo sin trabajarlas; además, se reglamentaba la venta y beneficio de los metales (Jinesta, 1938). El decreto 216 no abolió las Ordenanzas de Nuevo Mexico, lo cual no sucedió, sino hasta el año 1953 (Ulloa, 1979). En 1830, taambién se fundó la Casa de la Moneda, que funcionaba en el ingenio Los Horcones, localizada al oeste de la ciudad de Alajuela, donde se acuñaron doscientos mil pesos de cobre, de tres valores, un real, medio y el cuartillo (Jinesta, 1938).

Entre los extranjeros con experiencia en minería que se mencionan durante esta bonanza minera, que comprendió desde 1821 hasta 1843 (Araya Pochet, 1976), se mencionan nombres como el ingeniero británico Ricardo Trevinthick, el minero francés Santiago Millet, los italianos Domingo Matley, Mateo Bertora, Carlos Volio y Angel Franceschi, en la acuñación de monedas figuró el norteamericano Lawrence (Jinesta, 1938).

En este primer ciclo minero de Costa Rica se habla de las siguientes minas del Aguacate: Corralillo, La Minita, Los Castros, Machuca, Oreamuno, San Miguel, San Rafael (Ulloa, 1979). En 1835 habían siete minas, que producían cerca de dos y medio millones de pesos y empleaban a más de cuatrocientas personas (Fuentealba, 1977; Ulloa, 1979 y Villalta, 1986). González Flores (1976), refiriéndose a la economía inmediatamente post-independencia, escribe que: "Florece en este tiempo la industria minera, que viene a despertar la vida nacional del país y a estimular la inmigración extranjera. El arribo frecuente a nuestras costas de pequeñas embarcaciones, para transportar a Estados Unidos y a Europa los productos de nuestras minas, fomenta las relaciones comerciales con aquellos países...".

Los gobiernos costarricenses de la primera mitad del siglo XIX ven con buenos ojos los comentarios que se publicaban en diarios europeos con propaganda sobre Costa Rica. De esos 
discursos, tenemos uno que se refiere a las bondades de Costa Rica para que sea colonizada por extranjeros, como se lee a continuación:

“...Aunque esta república es incomparablemente más joven i pequeña que las que acabamos de mencionar (Chile, Perú $i$ Nueva Granada) sin embargo ella ofrece los mejores elementos de prosperidad, gracias á la fertilidad de sus tierras, á la riqueza de sus preciosos productos i á las ricas minas que oculta en todas sus montañas ... El que quiera hacerse cargo de la brillante posición á que está destinado este dichoso país ... se añaden las medidas adoptadas por el gobierno, para unirse por tratados honrosos, con las principales potencias europeas, para atraer los capitales extrangeros y la emigración europea..." (Journal de Courier de L Europe, reproducido en La Gaceta, 12 de junio de 1851).

Otra información contenida en un diario europeo, indica:

“... Este país, escondido hasta hoy, ofrece las mayores ventajas a la inmigración extrangera, su riqueza vegetal i mineral, $y$ particularmente las minas de carbón nuevamente descubiertas, ofrecen al emprendedor ventajas que, unidas á los esfuerzos que hace el actual gobierno para proteger toda clase de industrias, es dificil encontrar en cualquier otra parte de aquellos ricos y desolados paises..." (Le Pays, reproducido en La Gaceta de 12 de julio de 1851).

Un último ejemplo de la promoción para la inversión extranjera lo extraemos de otro periódico europeo: “...encontraron minas de carbón en [Costa Rica] y [este país está] dispuesta á recibir con los brazos abiertos, á todos los extrangeros que quieran ir á explotar su inmensa riqueza ... " (Le Courier de Nantes, según lo cita La Gaceta de 12 de julio de 1851).

Se observa que uno de los anzuelos que se lanzan a los aventureros de fortuna es sin duda alguna el de las minas, más cuando Estados Unidos está pasando en esa época por la fiebre del oro en la región de California. Las recientes exploraciones hechas en la actual Baja Talamanca como citamos supra: las de 1850-, abren todo un campo a la especulación de fabulosos yacimientos carboníferos, que están, sin duda, exagerados, para tentar a los aventureros e inversionistas.

La propaganda de Costa Rica orientada a la apertura de su mercado se vuelve a manifestar en 1862, cuando se participa en la Exposición Internacional de Londres [esta es la primera exposición de minerales, que participa Costa Rica en el extranjero y, se realizó el 1 de mayo de 1962]. Un extracto de un informe que George G. Ewen, cónsul de Costa Rica en esa ciudad, envía al gobierno de la República para comunicarle los resultados de la participación de Costa Rica en dicha exposición, dice:

“...Entre otros aspectos que Costa Rica cubrió en dicha exposición cabe destacar la colección de minerales que recibió la mención honrosa, lo que es tanto más meritorio, cuanto que se considera su producto muy superior al de algunas otras partes del mundo. Las especies minerales de las minas nombradas "Sacra Familia" (NE1) y "Quebrada Honda" (NE2) llamaba la atención especialmente, así como también la del "Cerro Atravesado" del mineral de hierro (NE186)..." (La Gaceta, 28 de marzo de 1863).

Durante la década de 1860, varios mineros europeos, posiblemente engolosinados por la propaganda sobre las riquezas mineras de Costa Rica, llegaron a explotar las minas localizadas en el monte del Aguacate. Así, en 1866, varias familias alemanas arribaron a Costa Rica, contratadas por la empresa minera de Paires, distrito de Santa Clara, en la provincia de Puntarenas (La Gaceta, 21 de Julio de 1866). Fue tan grande el auge de la minería durante la segunda mitad del siglo XIX, que La Gaceta, como diario oficial, mantuvo una sección que llamó "Registro minero", en la cual destacaba los datos más relevantes de varias minas activas por aquella 
época. En su número del 15 de agosto de 1866, se indica que son tres las principales minas, localizadas en los Montes del Aguacate, Paires de Santa Clara y Ciruelitas. La Sacra Familia la describen como una mina que por "...su forma jeológica y posición topográfica como por la fuerza y estabilidad de la veta, puede ser la más rica de Costa Rica..." Además, refiere que la Sacra Familia cuenta con dos vetas, una de oro y otra de plata. La actividad minera fue de gran importancia para el ámbito comercial en el siglo XIX, a juzgar por un comentario escrito en La Gaceta del 23 de octubre de 1869, en el que refiere que Costa Rica debe agradecer "...en gran parte su bienestar económico a la actividad minera..."

No cabe duda, entonces, que a finales de la década de los sesentas del siglo pasado, las expectativas mineras en Costa Rica, sobretodo con respecto al oro y al carbón, eran muy altas, aun más en zonas que aún se encontraban bastante inexploradas y de las cuales existieron antecedentes míticos de yacimientos, como en Talamanca. Veremos cómo esto influye directamente en la venida de William Gabb a Costa Rica.

En 1857 se descubre la mina de Paires y la de Ciruelitas en 1864, ambas en la cordillera de Tilarán. Para 1887 se conocían en Costa Rica 20 Minas: La Trinidad, Ciruelitas, Sacra Familia, La Unión, La Minita, Los Castro, San Rafael, Oreamuno, Quebrada Honda, Machuca, Peña Grande, Acosta, Las Cóncavas, Palmares, Mancuerna, Mata Palo, Puerta de Palacio, Hoja, Chiques y Chapernal (Jinesta, 1938). El mapa de Gabb (Petermann, 1877), incluía varias minas (Fig. 2).

\section{LAS LEYENDAS PERSISTEN EN EL SIGLO XIX}

Rafael Francisco Osejo, quien publica sus Lecciones de Geografía en 1833, en las cuales recupera las antiguas especulaciones coloniales sobre las minas del río La Estrella y del Tisingal, textualmente dice:

"Además de éstas [las minas del Aguacate], hay positivamente en todas las serranías que hasta ahora han sido visita- das, y sobre todo se halla la del Tisingal en las inmediaciones de las reliquias de la antigua ciudad de la Estrella, sita en uno de los excelentes puertos comprendidos en la ensenada de Boca-Toro. Algunos creen que la inmensa riqueza de esta mina y la circunstancia de hallarse sobre la costa del Mar Caribe, dió origen al nombre de Costa-Rica que conserva nuestro Estado." (von Frantzius, 1882).

Según el mismo von Frantzius (1882), a partir de este momento se habla no solo del Tisingal, sino también de la Estrella, en referencia a la antigua ciudad de la Estrella nombrada por Osejo, que según el historiador Fernández Guardia en realidad no parece haber existido ninguna ciudad con ese nombre en la actual Talamanca (Fernández Guardia, 1913).

El ingeniero inglés H. Cooper, quien estudió el camino de Cartago a Moín en 1838 hace excitativas para formar expediciones para ir en busca de las minas. Bülow, en 1849 dice: "Las minas más ricas se encuentran en el Monte-Aguacate, Tisingal, San-Mateo, San-Felipe, \&.: han sido explotadas por la Compañía Económica de Minas Anglo-Costa-Ricense, domiciliada en Lóndres, hasta ahora bajo la direccion de un Aleman, J. Brth." (von Frantzius, 1882). Lo cual según el mismo von Frantzius revela una confusión tremenda en cuanto a ubicación y nomenclatura.

El general norteamericano Tomás Francisco Meagher escribió lo siguiente:

"Tres siglos ha salian todos los años, de la boca del rio Estrella para Cádiz, dos galeones cargados con las lamas y metales de las célebres minas de oro y plata alli situadas. El monte impenetrable ha borrado las huellas de los Españoles, las ha hecho desaparecer del todo y quizas para siempre; $y$ todo cuanto se sabe en Costa-Rica y en otras partes de las estupendas minas de Estrella y Tisingal, es lo que nos han transmitido la tradición popular y la fantasía de los Indios." (von Frantzius, 1882). 


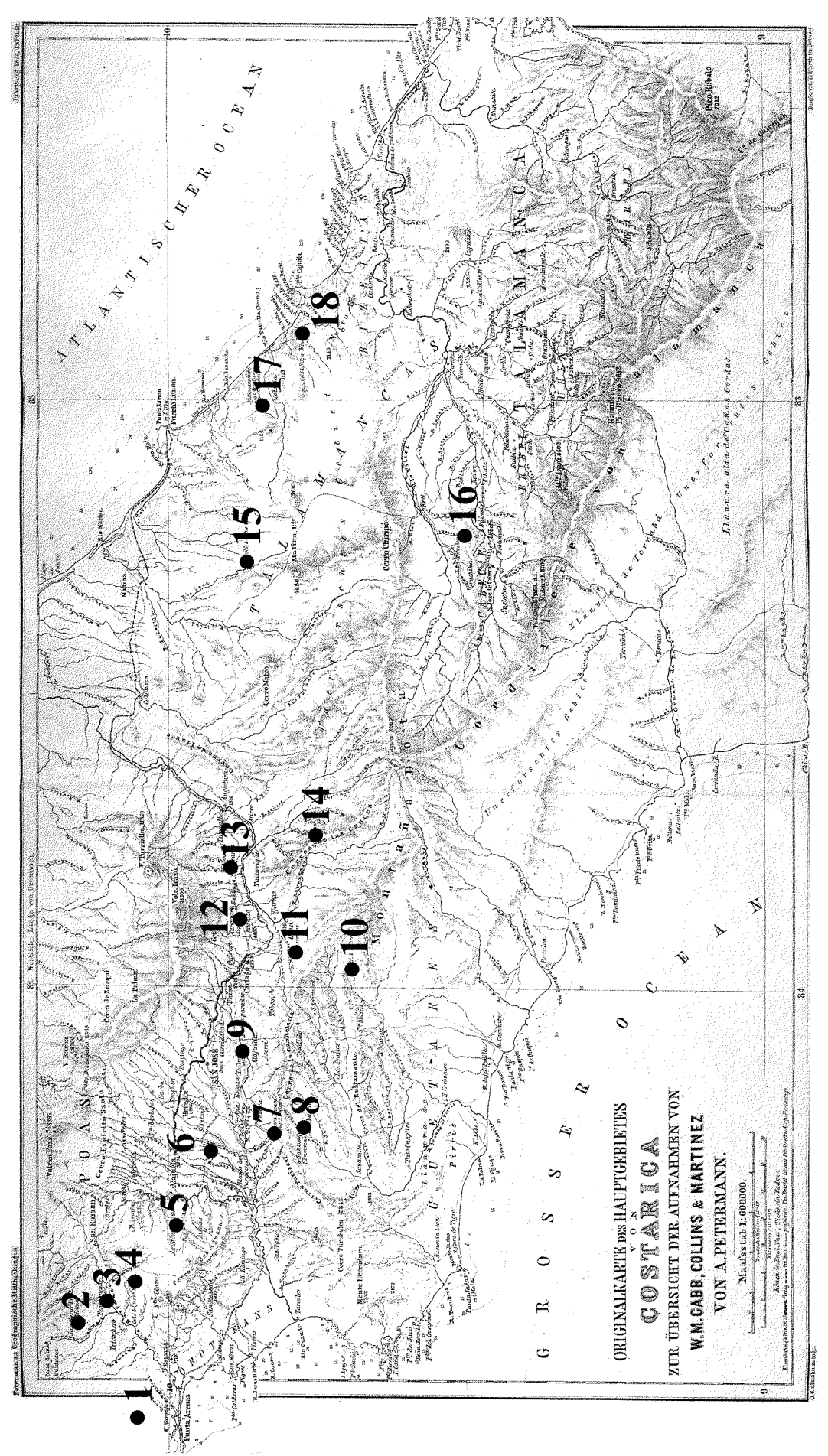



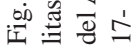


En enero de 1852 la Gaceta de Costa Rica publicó la noticia de un misionero que había penetrado en la Talamanca, y mencionaba que del cerro San Mateo, en Cabécar, se habían sacado grandes cantidades de oro en el siglo XVIII y que “... además de las de Tisingal había muchos otras minas de oro." (Fernández Guardia, 1968).

Felipe Molina, quien fue enviado a España, por el Gobierno de Costa Rica, en el año 1850 , con el fin de estudiar los documentos referentes a los derechos territoriales de Costa Rica, aparentemente no encuentra ningún documento sobre el Tisingal y solo dice: "Se supone que la mina de oro llamada Tisingal, que dió nombre al país, está situada cerca de la frontera de NuevaGranada en el Atlántico." (von Frantzius, 1882).

Después de un recuento sobre los esfuerzos para encontrar el Tisingal, von Frantzius en 1882 llega a la conclusión de que es imposible que el Tisingal se encuentre en el Caribe, más bien parece tener un origen Pacífico y, probablemente correspondieron a las minas existentes en el actual territorio hondureño.

\section{EXPEDICIONES EN BUSCA DEL TISINGAL}

Se hicieron por lo menos una decena de expediciones, realizadas por costarricenses, más otras de extranjeros, que muchas veces desembarcaban directamente en las cercanías del río Sixaola o en Bocas del Toro. Von Frantzius hace un recuento de estas travesías de lo que se presenta el siguiente resumen (von Frantzius, 1882).

La primera expedición del siglo XIX la realizó el aventurero, José María Figueroa, que salió de Cartago en 1843, pasó por Moín, Cahuita, hasta Cuabre, actual Bribri, hasta Pico Blanco (cerro Kamuk). Duró 6 meses en la travesía.

José María Figueroa emprendió otra gira de 4 meses, en 1845, pero esta vez se adentró en el río del Norte (actual río La Estrella), hasta sus nacientes. Figueroa consideraba que el oro se encontraba entre el río Tiliri (hoy día río Telire), afluente más occidental del Tarire (Sixaola) y el del Norte (von Frantzius, 1882). En sus expediciones encuentra una piedra de moler metales, y en un afluente del río Coen halló “oro lavado", lo que probablemente se refiere a placeres de oro.

En 1852, Francisco Gutiérrez, salió por el lado de Pacuare, donde conoció la planicie de Sahara, que posteriormente compró al Gobierno como tierra baldía y, es lo que hoy se conoce como Moravia de Chirripó, en donde tuvo noticias de oro en lo que se llama cerro San Mateo. Comparando la localización de este cerro en el mapa de Gabb, Collins \& Martínez (Petermann, 1877), con los mapas actuales del Instituto Geográfico Nacional, esta localidad está ubicada en los cerros Picada Matina, entre la laguna Ayil y Moravia de Chirripó. Las vetas aparentemente están del lado sureste.

Varias giras de búsqueda de minerales se realizaron al cerro San Mateo. En 1855 jefeada por Canuto Picado y luego José María Coronel en 1856 (que volvió en 1859) y finalmente Pedro Iglesias en 1858. En el año 1856 llegó una expedición de alemanes que estuvo unos 10 días cerca del Sixaola, sin poder dar razón siquiera de donde habían estado. En 1862, Manuel Marchena, quien tenía en su poder documentos de la misiones de Talamanca, sacados del convento de Orosi, se dirigió al río La Estrella. En 1863 Pedro Iglesias emprende una segunda expedición en el valle del Sixaola; halla lavaderos de oro en el río Coen y cerca de San José Cabécar.

En 1870 Eusebio Figueroa, realiza una nueva expedición, con base en documentos relativos a las minas de Costa Rica, que había traído de España (Fernández, 1882, p. 38). Había encontrado una transcripción del Registro Minero presentado por Vázquez de Coronado. Figueroa finalmente cedió este documento, junto con otros que han quedado inéditos, al Licenciado León Fernández, que lo publicó en su libro 3E, en el folio 18 hasta el 31. Esta expedición también fracasó (Fernández, 1882). José Figueroa realiza un nuevo viaje en 1874, para:

“...explorar los lavaderos antiguos para lo que llevaba los documentos antiguos que mi hermano [Eusebio] sacó de Sevilla y también aguardar a este que se fué para Norte America a buscar asociacion para el descubrimiento de las minas. Llegué a 
Limon alla nos embarcamos para bocas del Toro de ese puerto nos embarcamos para la punta Sarepta y tomamos por tierra hasta la boca del Changuinola. Subimos el rio y exploramos las antiguedades donde existian Cocburic, Quequeste y otras muchas antiguedades hasta que dimos con el punto de los minerales según las señales que daban los documentos, despues hicimos varias correrias por los escombros de pueblos viejos hasta llegar a la roca de la luna donde esta labrada y en donde segun la tradicion existió un Castillo de los Españoles, despues regresamos a Birsmaut- (Bear`s mouth) y fui por la punta de Pausac y quebrada del diablo antiguo cause del rio de la Estrella que desembocaba en la Bahía del Almirante..." (Arch. Nac. C.R., Albúm de Figueroa, viaje 36 ).

En 1875 José María Figueroa realiza el viaje 37, donde transcribe la búsqueda de las minas:

“...nos pusimos en comunicación atravesando del Sicsola y del Guabito al punto del mineral, en un brazo antiguo del Changuinola se formó el campamento general, alli comenzaron ya las exploraciones y estos trabajos dando pozos hasta de cinco baras sin poder dar en tierra firme, todo era arena acarreada por el rio. Alli cerca encontramos con Cameron y Juan Cooper 25 filetas en una roca de piedra viva con un altito a un lado donde lavaban el oro con unas sanjitas hechas en en la misma roca para traer el agua de una quebrada inmediata." (Arch. Nac. C.R., Albúm de Figueroa, viaje 37).

Las dos transcripciones de José María Figueroa revelan que sus exploraciones fueron hechas con base en interpretaciones del material documental traído por su hermano. Consideraba que el antiguo río de la Estrella, mencionado por el conquistador Coronado, no era otro que el actual Changuinola (Telorio) (Arch. Nac. C.R., Albúm de Figueroa, pág. 143), opinión que corres- ponde con Fernández Guardia. Estas opiniones contradicen las interpretaciones de von Frantzius que señala como el verdadero río La Estrella de Juan Vázquez de Coronado al río Sixaola (von Frantzius, 1882, p. 57-63).

Von Frantzius (1882, p. 39) concluye que: "El resultado final de tantos viajes se reduce, pues, á que en varios lugares de la cordillera se han encontrado metales que contienen oro, pero ninguna parte vestigios de una explotación antigua de minas en grande escala."

\section{INTENTO DE COLONIZACIÓN Y EXPLOTACIÓN DE TALAMANCA}

Los hermanos Keith, Minor y Henry Meiggs, llegaron con la construcción de ferrocarril al Caribe, iniciada por el general Tomás Guardia. Ambos eran profundamente ambiciosos y conocieron las leyendas del Tisingal y la Estrella. Minor Keith tuvo minas de hierro en Honduras, las minas de oro de Abangares, la Panama Corporation Ltd., dedicada a la minería de oro en ese país, y participa como accionista y vicepresidente de la Premier Gold Mining Company en la Colombia Británica. Su colección de oro indígena es calificada como extraordinaria por el New York Tribune (Salazar, 1996, p. 343-344).

Henry Meiggs junto con J.P. O’Sullivan, la compañía alemana Hübbe und Greytzell, Guillermo Nanne y Eusebio Figueroa [el mismo que había recopilado en España varios documentos sobre las minas del Tisingal], presenta una osada propuesta al gobierno de la República, fechada el 8 de abril de 1872, con lo cual intenta promover la colonización de un territorio que comprende desde el Río Banano en la costa del Atlántico y el Río General en la del Pacífico hasta la frontera de la Nueva Granada; así como para descubrir las riquezas metálicas de la región.

El territorio comprendido en esta propuesta incluye unos $13000 \mathrm{~km}^{2}$ del actual territorio de Costa Rica -lo que viene a ser un 25\%-, y abarca todo el sur de la provincia de Limón, casi toda la provincia de Puntarenas, y los extremos oriental de Cartago y sureste de San José, además de un grueso territorio de la actual Panamá, pues 
la frontera con la Nueva Granada o Colombia, en ese tiempo, se encontraba bastante más al este que hoy. Entre las variadas concesiones que solicitan del gobierno para su Compañía de Talamanca solicitan el derecho de fundar una o más colonias de extranjeros y concederles naturalización automática a los colonos que residan por más de dos años; dar principio a estudios topográficos por medio de una comisión científica; derechos de la propiedad de las vetas metálicas y cualesquiera otras como carbón o mármol, así como las maderas y cualesquiera otros productos de los terrenos, sin quedar sujeta en cuanto a las minas a los términos que las leyes del ramo fijan para su laboreo; exención de impuestos durante veinte años para los colonos; libertad sin prohibición gubernamental de montar cualquier industria; no pagar derechos de importación o exportación; al llegar a dos mil habitantes, la colonia elegiría sus propios regentes y reglamentos, aunque a los veinte años se convertiría en otra provincia de la República.

El vasto alcance de las concesiones solicitadas, equivalía a formar un territorio autónomo totalmente regalado, con la promesa de devolverlo dos décadas después. El proyecto es altamente ofensivo al orgullo de la nación, por lo que no sorprende que el Congreso lo rechace.

\section{RESULTADO DE LOS ESTUDIOS DE WILLIAM M. GABB}

Para prospectar los minerales ansiados, los Keith necesitaban de un geólogo y, terminan contratando a William More Gabb, quien finalmente trabaja para el gobierno. La investigación geológica de Gabb tiene objetivos muy definidos, sobre la búsqueda de las riquezas minerales de Talamanca, tectualmente dice: "Hice este estudio con especial empeño, a consecuencia de las muy esparcidas y acreditadas leyendas que colocan por allá ricas minas de metales preciosos, descubiertas y trabajadas durante algún tiempo por los españoles, hace unos siglos. Yo tenía instrucciones de dedicar mucha atención a Cabécar y lo hice en la esperanza de descubrir la famosa mina, cuya precisa localización se ha ol- vidado" (Gabb, 1895). Esto demuestra que los Keith y probablemente de Tomás Guardia, consideran que las minas se encuentran en el río Sixaola, específicamente en la zona de los indios Cabécares y río Coén; muy probablemente conocían la opinión de von Frantzius, que aunque se publicó en español hasta 1882, originalmente se había publicado en alemán, en 1869 (Gómez, 1977).

Con respecto al resultado de sus estudios sobre los depósitos minerales, Gabb afirma lo siguiente: “...la existencia de oro aquí es más que nada de interés científico que económico... Es suficiente decir aquí que tales minas no existen, para lo que hay suficientes razones geológicas..." (Gabb, 1875). Encuentra sin embargo, algunas vetas de cuarzo con algunas cantidades de oro, en general con muy difícil acceso (Gabb, 1875, p. 68). No deja de ser enfático, empero, para el desencanto de aquellos que confiaban en los descubrimientos de grandes minas, pues afirma: "Las supuestas minas de oro de Tisingal no pueden haber existido en el territorio explorado por mí."

Gabb concluye que la Talamanca no contiene riquezas minerales, lo que en la época constituye el desencanto de aquellos que lo habían traído para localizar, apropiarse y explotar las riquezas de Talamanca; con lo cual tal vez hemos tenido suerte, pues todavía conservamos la gran riqueza que representa esta región con su abundante flora y fauna, y como reserva de las pocas comunidades indígenas que quedan en el país.

\section{SUMARIO Y CONCLUSIONES}

Todos los datos e interpretaciones de investigadores durante dos centenios, parecen coincidir en que las famosas minas del Tisingal y La Estrella son más bien una exageración en parte y, una confusión causada por los problemas de nomenclatura geográfica y, la falta de mapas detallados del país y del resto de América Central. Además, el comercio existente entre los indígenas hace que el oro, el jade y otros bienes hayan sido usados en regiones donde no existen yacimientos. Un caso típico de esto es el jade que se ha encontrado en Costa Rica proveniente del comercio, pues en el país no existen yacimientos. 
El territorio que ahora es Costa Rica resultó ser muy pobre durante los tres primeros siglos después de la llegada de los españoles a América. No es sino hasta el descubrimiento del oro en los Montes del Aguacate, a principios del siglo XIX, que Costa Rica despega económicamente como una consecuencia directa de la bonanza minera de la primera mitad de este siglo. Indirectamente, la minería trae como resultado la modernización de la agricultura. Esta fiebre del oro, promueve de nuevo la codicia sobre las leyendas españolas del Tisingal y la Estrella, por lo que se hacen numerosas expediciones a Talamanca, tanto por nacionales, como por extranjeros, que muchas veces desembarcaban directamente cerca del Sixaola o en Bocas del Toro y, se internaban en los bosques buscando los preciados metales que supuestamente habían abandonado los españoles.

A finales del siglo XIX se dan las últimas consecuencias de las leyendas del Tisingal, en un intento de los hermanos Keith, junto con otros socios, por colonizar y explorar la Talamanca, lo que resulta en la traída de William M. Gabb, geólogo estadounidense, quien finalmente es contratado por el Gobierno de la República y, deja espléndidos trabajos geológicos y antropológicos sobre la Talamanca.

Probablemente, la mayor parte del oro que andaban los aborígenes de estas tierras provenía de la península de Osa y, en forma muy astuta deben haber confundido a los conquistadores españoles, quienes concentraron su búsqueda en el Caribe. Estos yacimientos de oro permanecieron ocultos durante todo el siglo XIX y primera mitad del XX.

En definitiva, las minas del Tisingal y/o La Estrella nacieron de una exageración y fueron fomentadas por la codicia y la confusión de nombres geográficos. Sin embargo, representan un pasaje interesante de nuestra historia y, la razón por la cual vinieron varios geólogos e ingenieros en minas, así como simples mineros extranjeros. Representó la esperanza de riqueza de varios costarricenses del siglo XIX, que entre otras cosas, deben haber invertido grandes cantidades de dinero en las expediciones, que a todas luces resultaron infructuosas.

\section{AGRADECIMIENTOS}

Los comentarios de Giovanni Peraldo y Franz Ulloa enriquecieron el manuscrito original. Rudolf Fischer consiguió una copia del mapa de Gabb, de la Fig. 2. Esta publicación se hizo en el marco de los proyectos de investigación: Análisis geo-estructural de Costa Rica, \# 113-90-071 e Historia de la Geología de Costa Rica, \# 113-97-249.

\section{REFERENCIAS}

ALVARADO, G.E., MORALES, L.D. \& SOTO, G.J., 1991: Historia del desarrollo de las Ciencias Geológicas en Costa Rica.- En: A.Ruiz (ed.): Estudios del pasado y del futuro: Ciencia y Tecnología. - Ediciones Guayacán, San José: 121-142.

ARAYA POCHET C, 1976: El segundo ciclo minero en Costa Rica (1890-1930).- 51 págs. Univ. C. R. Escuela de Historia y Geografía. Avances de Investigación, San José.

CASTILLO, R., 1983: Geología de Costa Rica: una sinopsis.- 182 págs. Ed. Univ. C.R., San José.

FERNÁNDEZ, L. , 1889: Historia de Costa Rica durante la dominación española 1502-1821.- 640 págs. Impresor de la Real Casa, Tipografía de Manuel Ginés Hernández, Madrid.

FERNÁNDEZ, L., 1882: Colección de documentos para la historia de Costa Rica.- 483 págs. Imprenta Nacional. Tomo II, San José.

FERNÁNDEZ GUARDIA, R., 1908: Cartas de Juan Vázquez de Coronado nuevamente publicadas por D. Ricardo Fernández Guardia.- 68 págs. Imprenta de la Vda de Luis Tasso, Barcelona.

FERNÁNDEZ GUARDIA, R., 1913: History of the Discovery and Conquest of Costa Rica.- 416 págs. Crowell Company Publishers, Nueva York.

FERNÁNDEZ GUARDIA, R., 1968 [2a ed.]: Reseña histórica de Talamanca.- 135 págs. Imprenta Nacional, San José.

FERRERO, L., 1978: William M. Gabb y Talamanca. Presentación del libro Talamanca, el espacio y los hombres: VII-LXXIX.- Ministerio de Cultura Juventud y Deportes, San José.

FERRERO, L.; 2000: ¿Por qué prehistoria si hay historia precolombina? .- 272 págs. EUNED, San José. 
FRANTZIUS, A. von, 1882 [se consultó la segunda edición publicada en 1965]: Acerca del verdadero sitio de las ricas minas de Tisingal y Estrella, buscadas sin resultado en Costa Rica.- En: Fernández, L.: Colección de documentos para la historia de Costa Rica.- Tomo II:23-73, Imprenta Nacional, San José.

FUENTEALBA, N., 1977: El derecho minero de Costa Rica.- 169 págs. Ed. Univ. C. R., San José.

JINESTA, R., 1938 [2da. edición del original de 1986] : El oro en Costa Rica.- 32 págs. Imprenta FALCO, San José.

GABB, W.M.,1875: Notes on Costa Rica geology.- Am. J. Sci., 9: 198-204.

GABB, W.M., 1895: Informe sobre la exploración de Talamanca verificada durante los años 1873-1874 (Introducción de Henri Pittier).- 89 págs. Tipografía Nacional, San José.

GÓMEZ, L.D., 1977: Bibliografía geológica y paleontológica de Centroamérica y El Caribe.- 123 págs. Museo Nacional de Costa Rica, San José.

GONZÁLEZ FLORES, L.F., 1976 [El original fue publicado en 1921]: Historia de la Influencia Extranjera en el Desenvolvimiento Educacional y Científico de Costa Rica.- 296 págs. Editorial Costa Rica, San José.

MELLIS, E., 1891: Las minas del Monte del Aguacate y de Los Castros [traducido al español por Manuel Carazo Peralta y anotado por Francisco María Iglesias].20 págs. Instituto Físico-Geográfico Nac. de C. R..Tipografía Nacional, San José.

PETERMANN, A., 1877: Wm. Gabb's Aufnahme von Talamanca un der kartographische Standpunkt von Costa-Rica in 1877. Gotha 23:385-387 + mapa.
PITTIER, H., 1893: Nombres geográficos de Costa Rica. Anales del Instituto Físico Geográfico de Costa Rica VI:95-107.

RIVAS, F., MELÉNDEZ, C. \& ARREA. F., 1989: Historia General de Costa Rica (Volumen 2).- 487 págs. Euroamericana Ed. Costa Rica, San José.

SALAZAR NAVARRETE, J.M., 1996: La gran serpiente verde.- 367 págs. EUNED, San José.

THIEL, B.A., 1894: Informe de los misioneros franciscanos.Anales del Instituto Físico Geográfico Nacional C.R., VII: 71-96 + mapa.

ULLOA, F., 1979: Historia minera en Costa Rica.- 50 págs. Dir. Geol., Minas y Petróleo, San José.

VÁZQUEZ DE CORONADO, J., 1908: Cartas de Juan Vázquez de Coronado nuevamente publicadas por D. Ricardo Fernández Guardia.- 68 págs. Imprenta de la Vda. De Luis Tasso, Barcelona.

VILLALTA, C., 1986: La explotación de oro en Costa Rica.Rev. Geol. Amér. Central, 5:109-113.

\section{INFORMACIÓN HEMEROGRÁFICA Y DE ARCHIVO}

Revista de Archivos Nacionales 1938(3)

Albúm de Figueroa, Archivos Nacionales de Costa Rica

La Gaceta, 12 de junio de 1851).

La Gaceta de 12 de julio de 1851.

La Gaceta, 28 de marzo de 1863.

La Gaceta, 21 de Julio de 1866.

La Gaceta del 23 de octubre de 1869. 